\title{
DHM an Aid for Virtual Ergonomics of Manufacturing Shop Floor: A Review with Reference to Industrially Developing Countries
}

\author{
Sanjog J. \\ Dept. of Design, \\ Indian Institute of \\ Technology \\ Guwahati, \\ Guwahati-781039, \\ Assam, India
}

\author{
S Karmakar \\ Dept. of Design, \\ Indian Institute of \\ Technology \\ Guwahati, \\ Guwahati-781039, \\ Assam, India
}

\author{
T Patel \\ Agricultural Engg. \\ Dept., NERIST, \\ Nirjuli-791109, \\ Arunachal Pradesh, \\ India
}

\author{
A Chowdhury \\ Dept. of Design, \\ Indian Institute of \\ Technology \\ Guwahati, \\ Guwahati-781039, \\ Assam, India
}

\begin{abstract}
Manufacturing strategies adopted by majority of industries in third world/industrially developing countries especially in India and China are still far from world class practices. Competition due to entry of multinational companies is forcing them to turn their attention to seek improvements for long term survival and associated benefits. Ergonomics, more specifically computer aided ergonomics finds a low level of acceptance in manufacturing industries and thus results in poorly designed work system/place, low productivity and prevalence of musculoskeletal problems in industrial workforce. Taking these facts into consideration an effort has been made through extensive literature review to highlight relevance of digital Human Modeling Software (DHMS) as a tool for evaluating, improving existing/ proposed manufacturing workstation/ workplace, and its associated tasks. Attempt has also been made to encourage manufacturing industries (including small and medium scale industries that are unaware of this technology) in developing countries to focus their attention towards this exceptionally useful tool for their betterment. It is strongly recommended that industrial/ production engineers can certainly without any doubt advocate use of DHM as an indispensible tool for developing human centered manufacturing work station/ workplace and harness its benefits.
\end{abstract}

\section{Key Words}

computer aided ergonomics, digital human modeling, manufacturing, industrially developing countries

\section{INTRODUCTION - MANUFACTURING AND ITS HUMAN CENTREDNESS}

Manufacturing is a process of converting raw materials into finished goods through a production process involving machine, tools and labour (men). Mass production of standardized products is widely adopted by firms nowadays as unit costs are lowered by this form of manufacturing. Mass production brings about standardization in manufacturing industries thus making the job to be completed in few steps with workers (characterized by varied anthropometry and abilities/capabilities) performing standard tasks [1] which may be repeated thousands of times a day in standardized work places forcing them to adapt, resulting in musculoskeletal disorders/ cumulative trauma disorders/ repetitive motion syndromes [2].
Conventional approaches to workplace design mostly overlook problems related to anthropometric and biomechanical aspects of performing a task which are an indispensible part in workplace designs [3]. Computer aided ergonomics has found very little mention in highly advanced computer integrated manufacturing techniques/strategies adopted in today's manufacturing sector [4] as styling and engineering design elements are given much importance [5]. Since ergonomics finds a low level of acceptance and limited number of applications, it has resulted in poorly designed work systems in manufacturing industries causing serious work related health complications among workers [6]. Unsatisfactory production ergonomics is the leading cause of sick leave and work injuries in manufacturing industry [7]. It is also observed that since technical and cost considerations play a major role in production designs, attention to human factors considerations come after addressing other design factors/ problems whereas typical manufacturing workstation activities where ergonomics plays a vital role should be simultaneously considered in design process to guarantee good usability and overall performance while avoiding extra costs of redesign and corrective actions [8]. Hanson et al. (2009) [9] from a survey of literatures stressed the need of anthropometrics to be compared with product and workplace measurements in an ideal design process since fit between products, workplaces and users is not always optimal thereby leading to musculoskeletal disorders.

\section{DHM IN INDUSTRIALLY DEVELOPING COUNTRIES}

Digital human modeling technology has also now been used in industrially developing countries like Brazil, China, Taiwan, India, South Korea, Thailand and Egypt [10], [11], [12], [13], [14], [15], [16], [17], [18], [19], [20], [21], [22], [23], [24], [25]. It is to be noted that Taiwan and South Korea are recently being categorized as graduated developing/advanced economies. Applications of DHMs in developing countries are limited or confined to product design, footwear/shoe rack design, man-machine compatibility studies, assessment of sizing systems, assembly operation in automobile industry, military workstation design, cockpit design, biomechanical evaluation, footwear design, occupational health and safety study etc.

From above mentioned literatures, it is clearly visualized that application of DHM for virtual evaluation of manufacturing workstations and associated tasks is less reported in those 
countries. Methodologies adopted in some of these literatures are highlighted below to help readers gain valuable insights. Product design applications included investigations of a radial drilling machine involving assessments of upper limb with help of inbuilt ergonomic tool named Rapid Upper Limb Assessment (RULA) and biomechanical evaluations [10]. Biomechanical singular action and push pull analysis with load definition was utilized in a descriptive study to judge pushing and pulling job (with load carrying) in industrial sector [10]. Intention of another novel study with focus on product design was to build up virtual human models, along with a new biomorphic tool to simulate postures of actual humans [15]. Daily activities in a residential environment (accessing locks, use of bathroom, opening of doors and drawers of furniture) were investigated in a virtual environment for studying accessibility in a social housing project [10]. A three dimensional procedure for studying a sizing system is claimed to provide an economical, quick and quantitative technique for facilitating critical fit assessment as in case of helmets [11]. Integration of dynamic simulation and ergonomic analysis was applied to assess automobile assembly tasks leading to improvements from human factors point of view [13]. This study considering workplace evaluations in digital environment had prevention of workrelated musculoskeletal disorders as its objective. Human modeling software was profitably employed to assess a simple concept model of a shoe rack with respect to reach, vision, and capability of anticipated users to perform certain specific tasks (shoe lace tying/untying etc.) [18]. It was realized during course of above work that posture editor and inverse kinematics features were found to be handy in giving realistic, context specific postures for digital humans as adopted by real humans. Further it was also established with help of case study that evaluation of ingress-egress process (via rear door along with ladder supports) for a crew cabin of army vehicle in a simulated atmosphere of CAD software in normal and emergency scenarios is achievable without trials by means of real people and physical mockups [16]. Investigations considering virtual ergonomic appraisal of pilot's vision in a jet aircraft demonstrated usefulness of vision analysis tools of digital human modeling software [17]. Vision analysis tools like view cones, eye view windows, blind spot area, obscuration zone, reflection zone etc. were engaged for evaluation of visual fields in addition to observe kinematic changes of body joints during gazing task. The authors observed that such tools in DHM software are very helpful in investigations regarding placement of displays and controls depending on their importance within visual fields and anthropometry of intended users. Geometric procedures for understanding uniqueness of human visual capabilities proved to be very useful for estimating visual performance of intended user groups as described in one of the studies [19]. Conceptualizing task dependent boundary-manikin capable of varying its dimensions with respect to a task was formulated in a study and is expected to help in identifying people to perform a particular task [20]. Reach probability was calculated in a 3D grid to achieve the goals of above mentioned research work. Computer vision system capable of analyzing and measuring human joints movements providing an alternative to manual instruments such as goniometer, inclinometer or a tape was proposed in another research work [25]. It is claimed that the above development facilitates precise measurements without using costly sensors or special environments. A method for modeling of human using a series of rigid links connected by joints was also discussed in above mentioned study. Human gait motion can be simulated (using motion analysis system) and footwear deformation can be determined including visualization of stress distribution as shown in a particular study [14]. Task analysis tool features in DHM software were utilized for ergonomic evaluation of meal serving tasks during peak hours in a Chinese University cafeteria [24]. The above study yielded results necessitating some policy changes to be adopted and recommended reducing load on workers' hands.

From a survey it is evident that manufacturing strategies adopted by Indian companies are reported to have a similarity with third world countries which are still far from world class practices [26] and entry of multinational companies with resulting competition are forcing them to look for continuous improvements to remain functioning in globalised market conditions. A comparison between China and India which are predicted to become major players in the globalised world economy based on real output and labour productivity in manufacturing between 1980 and 2002, reveal high growth rate for Chinese firms [27].

\section{RELEVANCE OF PRESENT REVIEW}

Human capabilities and limitations should be considered in addition to technical specifications while designing manufacturing systems [28]. As it is also reported that majority of small and medium scale industries (where non repetitive activities exist which could be hazardous to workers) are still unaware of DHM simulation tools [29]. It will be highly useful to understand and highlight application and benefits of DHM for ergonomic evaluation of workstations in industrially developing countries for betterment of manufacturing industries.

\section{METHODOLOGY ADOPTED}

A systematic approach was adopted to search published literatures/articles written in English-language from electronic databases: science direct, springerlink, tandfonline, google scholar, etc. Available hard copy journals articles and books were also studied. All publications identified following online literature search were studied thoroughly at least by titles and abstracts.

\section{NEED FOR DHM INCLUSIVE APPROACH IN EVALUATION OF MANUFACTURING WORKSTATIONS}

Traditional ergonomic analysis involving physical mockups of product, workspace and real workers being used in different combinations is both time consuming and costly [16] thereby does not confirm to goals of modern industry rendering it practically not feasible [30]. Further once any workstation is developed and commissioned there exists only a remote chance of making additional design changes without incurring huge additional expenditure and time [17]. Goal of manufacturing industry to achieve human integrated design of products and process [31] can be achieved only if abilities of operator are matched with task requirements as well as with working environment with due consideration to physical constraints [32]. In this context DHM software provides an excellent opportunity for accomplishing ergonomic assessments as it is interfaced with $3 \mathrm{D}$ computer aided designs thereby reducing a number of assumptions on which traditional ergonomic evaluations are grounded upon [33]. Interactions between workers and their working environment always provide challenging problems due to high complexity of manufacturing systems [34]. DHM along with computer aided workplace designs can help in completing entire ergonomic evaluations (exact quantification and measurement 
of ergonomic factors) using numerous virtual setups of workspace incurring less time and cost when compared with traditional analysis [31], [35]. DHMs capability to interact with digital workstations and subsequently virtual evaluations of workstation layout, workflow simulation, assembly accessibility, reach, clearance, strength capability studies, safety analysis, assembly feasibility, process compatibility issues, posture and movement simulations (arms, legs, torso) using inverse kinematics, vision simulation, joint dependent comfort/discomfort evaluations, maximum force calculations, center of gravity analysis together with generation of large amount of biomechanical information (Spinal compression, shear forces etc.) based on thousands of postures from an entire task simulation is more than an ergonomist has had before [36], [33] and it facilitates a complete data based ergonomic analysis and provides strong scientific validity to solutions proposed or implemented. Biomechanical assessment like overexertion of lumbar spine (from assessing lumbar load) for investigating occupational health activities even with additional help of gender-related limits based on load-bearing capacity of spinal elements is very useful for predicting occupational health risks [37].

It is highly worth mentioning at this juncture that Longo and Monteil (2011) [32] has identified ergonomics, work measurement and combination of above two with inclusion of DHMs as three main scientific approaches for workplace design with the latter approach always providing researchers and practitioners with challenging problems.

\section{ERGONOMIC ASSESSMENT OF MANUFACTURING WORKSTATION AND ITS BENEFITS- EXAMPLES}

DHM has been a major research topic within various academic circles for the past ten years [38]. Manufacturing industry in industrially developed countries has benefitted when DHM was used for manufacturing workstation/workplace evaluations as can be envisaged from following paragraphs. For readers who have engineering concerns in mind it will be enlightening to note than DHM addresses some of them too.

Mavrikios et al. (2007b) [31] used posture based ergonomic analysis to arrive at certain inferences relating to ergonomic efficiency of process (identification of critical points based on comfort scores resulting in redesign of actions to reduce worker's fatigue and task's execution time to ergonomically optimize the task) in design of assembly workplace for a commercial refrigerator manufacturing industry. DHM with reasonable accuracy addresses reachability concerns in production work places and is also useful to design dimensions of production assembly, geometric design of equipment according to anthropometric demands [39] and in addition it can also be used to analyze existing human motions, lifting behaviors with respect to current/mock-up work stations and then modified for different scenarios for different statures, alternative workstation geometries while taking into account lower back compression forces, joint strength requirements, effects of stature on biomechanical stresses etc. and propose modified workstation designs and thus improve design layouts [40]. Cimino et al. (2009) [34] proposed a methodology for ergonomic design of industrial workstations (high pressure hydraulic hose manufacturing) based on multiple design parameters (objects dimensions, tools position, operator work methods) affecting performance measures related to work measurement and ergonomics, supported by a simulation model that recreates workstations in a 3-D virtual environment along with inclusion of digital human models. Another case study in a workspace involving a worker, milling machine and its associated tasks (bringing and registering the board, charging $\mathrm{NC}$ part program, cleaning and placing the board in pallet) were simulated and investigated using DHM and it was found that such ergonomic analysis made possible reduction of idle time and simulation for a wide range of workplace scenarios [29]. In a review regarding industrial workstation design based on DHM and simulation by Longo and Monteil (2011) [32], it was revealed that majority had ergonomic objectives in mind followed by safety and operational goals and studies mostly resulted in layout rearrangement while some studies resulted in hazardous movement changes and organizational changes.

Finally automobile manufacturing sector has also seen instances where DHM was applied to practical use successfully. Peacock et al. (2001) [41] of manufacturing ergonomics laboratory, General Motors Corporation observes that sheet metal handling is a complex process where production rates in certain sections are governed by the process, need to maintain sufficient inventory levels for meeting production requirements and high capital costs of equipment necessitates continuous production at full capacity with least down time. They have opined that in such a demanding scenario spatial characteristics of workplaces (heights, orientations, reaches, and accessibility) and qualitative, quantitative questions regarding physical parameters of task (weights, shapes, clearances, distances, locations, orientations, pathways, movements, moments, targets and interfaces) need to be optimized for collision free environment between parts, equipments and people which require sophisticated ergonomic analysis. In this context DHM was successfully used (to examine a sheet metal handling process) and important policy decisions were arrived at. Participatory ergonomics approach with inclusion of DHM in ergonomic analysis has resulted in design changes facilitating decreased assembly times, work related physical stress and reduced rework thus improving assembly work in automotive industry [42]. Evaluation of ergonomics and worker safety issues were studied while installing a new satellite digital antenna radio system at Ford Motor Co. and it is opined that DHM facilitates cost savings in real terms by integration of design, management, marketing, manufacturing, training departments within a company when integrated with product lifecycle management software [43]. Since workstation modifications are costly, reactive and iterative process (as traditional measurements of forces, joint angles, and time studies relied on observing an operator on assembly shop floor) it is noteworthy to know that ergonomic requirements for assembly operations are starting to be included as a part of engineering automotive manufacturing curriculum [33]. Lämkull et al. (2009b) [44] reported that relationship between ergonomics with manufacturing quality, time to market, musculoskeletal disorders and their combined implications on productivity are major reasons for use of DHM tools in automotive manufacturing industry. They also highlighted that DHM tools with the advantage of having statistical description of population attributes (size, range of motion etc.) are applied in design, modification, visualization, and analysis of workplace layouts. DHMs are also widely utilized to predict postures and ergonomic stresses accompanying automotive assembly tasks including manual assembly tasks for providing designs for standing and unconstrained working postures [7]. 


\section{CONCLUSION}

Man machine/equipment interaction which happens in work station is an indispensible part in manufacturing environment wherein lies tremendous scope for ergonomic improvements through proper design. Widespread prevalence of MSDs in today's manufacturing scenario justifies need to design production systems that fit workers' structural and functional anthropometry. Reduced frequency and severity of accidents, improved job performance, fewer days lost to injuries, improved user acceptance, improved efficiency, improved effectiveness, reduced design and manufacturing costs, increased standardization, shorter training time, protection from litigation, greater job satisfaction, less employee turnover, less user fatigue are some of immense benefits of proactive ergonomics [45], which manufacturing industries in industrially developing countries can/should utilize with help of DHM as a lack of published literatures in framework of manufacturing workstations/shop floor in industrially developing countries is observed. Ergonomic evaluations by exploring what if scenarios with quick information by providing details about population capabilities and specific outputs with reference to specific design attributes of interest greatly benefit engineers and designers [38] in design of human centered manufacturing workstations.

It is clearly evident from above review that DHM addresses issues/concerns like workstation layout, workflow simulation, assembly accessibility, reach, clearance, strength capability, safety analysis, assembly feasibility, process compatibility, posture and movement simulations, vision simulation, joint dependent comfort/discomfort evaluations, maximum force calculations, center of gravity analysis, biomechanical analysis and unintentional/ hazardous human machine contact/interaction. Its application has resulted in redesign of actions to reduce worker's fatigue and task's execution time, propose modification in workstation designs, improve layout designs, design dimensions for production assembly and equipments, and it has also helped to reduce assembly times, physical work in machine shop of manufacturing industries which ergonomist, engineers and designers aim at. At the same time let's not forget that ergonomics will play a vital role in increasing comfort and productivity if active participation from users and management are forthcoming [46] which should be understood and put into practice with active collaboration between academia and industry [18].

Simulation using DHM software appears to be a necessary condition to accomplish proactive ergonomics [47] and also for evaluating and modifying existing manufacturing workstations without disturbing existing manufacturing activities in the production line. Chaffin, (2001) [48] had stated that DHM is moving into mainstream design for workplaces while Hanson et al. (2006) [49] has inferred from other DHM users that human modeling tools will bring about development of a standard ergonomic evaluation methodology thus ultimately becoming a standard validation and benchmarking method.

DHM inclusive approach is being utilized predominantly by industries/businesses in industrially developed countries as envisaged from published literatures. Therefore we strongly advocate the necessity of developing and implementing human centered workplace with help of computer aided ergonomics incorporating DHM as one of the important manufacturing strategies to improve productivity and other relevant parameters in manufacturing industries for industrially developing countries to survive and remain globally competitive. While suggesting above recommendation, it is comprehended that there is need to educate manufacturing industries including small scale enterprises to make them understand long term benefits realizable in product and workstation design using DHM systems.

Reasons for lack of widespread application of DHM technology in developing countries can be attributed to difficulty in incorporating customized data base in software due to lack of appropriate national anthropometric data bases in most of the developing countries, except few like China and South Korea [51][52]. Moreover, huge ethnographic variations due to mixing of various races make it difficult to develop national anthropometric and biomechanical data base for countries like India. DHM tools require substantial monetary investments and training which can be afforded mostly by large and resourceful companies (Laring et al., 2005) [52] in developed countries. Lack of awareness is another factor contributing to negligible application of this technology in fast developing economies like India, Pakistan, Bangladesh, Russia, Syria, Thailand and other similar countries. Authors of the current paper believe that low rate of progression in Information Technology (IT) and less adoption of advanced computing techniques might be important factors behind less use of CAD and DHM in many developing countries.

Finally it is felt that above discussion will not be complete without briefing readers a latest happening in the realm of DHM. Quoting the reality that DHM software existing in market is developed for specific applications thus appreciably resulting in non compatible results, dearth of model data related standards, incapability to exchange results or upgrade to another DHM system, lack of clarity on the subject of validity pertaining to anthropometric and biomechanical data, Paul and Wischniewski (2012) have stressed the need and conversed on topic of standardization of digital human models [53]. They have highlighted previous efforts in this regard and also stated a course of action to be adopted in future.

\section{REFERENCES}

[1] Barnes, R. M., 1980, Motion and time study. $7^{\text {th }}$ ed. New York: John Wiley \& Sons, Inc. ISBN 0-471-08335-6.

[2] Ostrom, L. T., 1993. Creating the ergonomically sound workplace. San Francisco: Jossey- Bass Publishers Inc., ISBN 1-55542-621-2.

[3] Jensen, P. L., 2002. Human factors and ergonomics in the planning of production. International Journal of Industrial Ergonomics, 29, 121-131.

[4] Sanjog, J., Chowdhury, A. and Karmakar, S., 2012a. Digital Human Modeling Software in Secondary Manufacturing Sector: A review. In Proceedings of International Conference on Recent Trends in Computer Science and Engineering (ICRTCSE-2012), 3-4 May, 2012, Chennai, India.

[5] Summerskill, S. J. and Marshall, R., 2011. Digital Human Modeling in the User-Centered Design Process. In W. Karwowski, M. M. Soares, and N. A. Stanton, eds. Human Factors and Ergonomics in Consumer Product Design, New York: Taylor \& Francis, 293-324.

[6] Shikdar, A., Al-Araimi, S. and Omurtag, B., 2002. Development of a software package for ergonomic assessment of manufacturing industry. Computers \& Industrial Engineering, 43, 485-493. 
[7] Lämkull, D., Hanson, L. and Ortengren, R., 2009a. A comparative study of digital human modeling simulation results and their outcomes in reality: A case study within manual assembly of automobiles. International Journal of Industrial Ergonomics, 39, 428-441.

[8] Helin, K., Viitaniemi, J., Montonen, J., Aromaa, S. and Maatta, T., 2007. Digital Human Model Based Participatory Design Method to Improve Work Tasks and Workplaces. In V.G. Duffy, ed. Digital Human Modeling, LCNS 4561, Springer, 847-855.

[9] Hanson, L., Sperling, L., Gard, G., Ipsen, S. and Vergara, C. O., 2009. Swedish anthropometrics for product and workplace design. Applied Ergonomics, 40, 797-806.

[10] Okimoto, M. L. L. R., 2011. Digital Human Modeling in Product Evaluation. In W. Karwowski, M. M. Soares, and N. A. Stanton, eds. Human Factors and Ergonomics in Consumer Product Design, New York: Taylor \& Francis, 325-331.

[11] Wu, J., Li, Z. and Niu, J., 2009. A 3D Method for Fit Assessment of a Sizing System. In V. G. Duffy ed. Digital Human Modeling, HCII 2009, LNCS 5620, Springer-Verlag Berlin Heidelberg, 737-743.

[12] Lin, Y. L. and Wang, M. J. J. 2012. Constructing 3D human model from front and side images. Expert Systems with Applications, 39, 5012-5018.

[13] Chang, S. W. and Wang, M. J. J., 2007. Digital human modeling and workplace evaluation: Using an automobile assembly task as an example: Research Articles. Human Factors in Ergonomics \& Manufacturing - Advances in Agile Enterprises, Part I. UK: John Wiley and Sons Ltd., 17(5), 445-455. (ISSN: 1090-8471 EISSN: 1520-6564)

[14] Minga,T. Y. and Chuenb, H. K., 2011. Human foot modeling towards footwear design. Computer-Aided Design 43, 1841-1848.

[15] Chiou, Wen-Ko, 2010. Landmark effect in Digital Human Model simulation tasks by using the biomorphic tool. In proceedings of $3^{\text {rd }}$ Conference on Human System Interactions (HSI), 13-15 May 2010, Rzeszow, 308 312.

[16] Karmakar, S., Majumdar, Deepti., Pal, M.S. and Majumdar, D. 2011. Ergonomic Study of Ingress-Egress of an Army Vehicle in Simulated Environment, In Proceedings of International Conference on Trends in Product Lifecycle, Modeling, Simulation and Synthesis (PLMSS)-2011, Bangalore, India. 69-74.

[17] Karmakar, S., Pal, M. S., Majumdar, Deepti and Majumdar, D. 2012. Application of digital human modeling and simulation for vision analysis of pilots in a jet aircraft: a case study. Work, 41, 3412-3418.

[18] Sanjog, J. Karmakar. S. Agarwal, H. and DattuPatil, C., 2012b. Designing and ergonomic evaluation of a shoe rack in CAD environment. International Journal of Computer Applications, 49 (20), 38-41.

[19] Vinayak and Sen, D., 2012. A vision modeling framework for DHM using geometrically estimated FoV. Computer-Aided design, 44, 15-28.
[20] Reddi, S. and Sen, D., 2008. Task Dependent Boundary Manikins in Statistical DHM. SAE Technical Paper 2008-01-1890, doi:10.4271/2008-01-1890.

[21] Jung, K. Kwon, O. and You, H., 2009. Development of a digital human model generation method for ergonomic design in virtual environment. International Journal of Industrial Ergonomics, 39, 744-748.

[22] Baek, S. Y. and Lee, K., 2012. Parametric human body shape modeling framework for human-centered product design. Computer-Aided Design, 44, 56-67.

[23] Ming, T. Y. and Chuen, H. K., 2011. Human foot modeling towards footwear design. Computer-Aided Design, 43, 1841-1848.

[24] Niu, J. W., Zheng, X. H., Zhang, L., Xu, S. Y., Li, X., Guo, S. S. and Ding, S.T., 2011. Investigation of Ergonomics in Chinese University Cafeterias' Working Situation at Peak Hours Using Jack. In Proceedings of IEEE $18^{\text {th }}$ International Conference on Industrial Engineering and Engineering Management. Changchun. 595-599.

[25] Adly, A. S., Abdelhalim, M. B. and Badr. A., 2012. Analyzing and Measuring Human Joints Movements using a Computer Vision System. International Journal of Computer Applications, 45 (20), 21-29.

[26] Dangayach, G. S. and Deshmukh, S. G., 2000. Manufacturing Strategy: Experiences from Select Indian Organizations. Journal of Manufacturing Systems, Vol. 19, No. 2, 134-148

[27] Lee, B. L., Rao D. S. P. and Shepherd, W., 2007. Comparisons of real output and productivity of Chinese and Indian manufacturing, 1980-2002. Journal of Development Economics 84, 378-416.

[28] Shahrokhi, M. and Bernard, A., 2009. A framework to develop an analysis agent for evaluating human performance in manufacturing systems. CIRP Journal of Manufacturing Science and Technology, 2, 55-60.

[29] Santos, J., Sarriegi, J. M., Serrano, N. and Torres, J. M., 2007. Using ergonomic software in non-repetitive manufacturing processes: A case study. International Journal of Industrial Ergonomics, 37, 267-275.

[30] Mavrikios, D., Pappas, M., Kotsonis, M., Karabatsou, V. and Chryssolouris, G., 2007a. Digital Humans for Virtual Assembly Evaluations. In V.G. Duffy, ed. Digital Human Modeling, LCNS 4561, Springer, 939-948.

[31] Mavrikios, D., Karabatsou, V. Pappas, M. and Chryssolouris, G., 2007b. An efficient approach to human motion modeling for the verification of humancentric product design and manufacturing in virtual environments. Robotics and Computer-Integrated Manufacturing, 23, 533-543.

[32] Longo, F. and Monteil, N. R., 2011. Industrial Workstation Design Based on Digital Human Modeling and Simulation: A Review. SCS M\&S Magazine - n3 (July), 133-141.

[33] Stephens, A. and Jones, M. L. H., 2009. Workplace Methods and Use of Digital Human Models. In V.G. Duffy, ed. Handbook of DIGITAL HUMAN MODELING, USA: Taylor and Francis, 6.1-6.11. 
[34] Cimino, A., Longo, F. and Mirabelli, G., 2009. A multimeasure-based methodology for the ergonomic effective design of manufacturing system workstations. International Journal of Industrial Ergonomics, 39, 447455 .

[35] Jayaram, U., Jayaram, S., Shaikh, I., Kim, Y. J. and Palmer, G., 2006. Introducing quantitative analysis methods into virtual environments for real-time and continuous ergonomic evaluations. Computers in Industry, 57, 283-296.

[36] Bubb H. and Fritzsche, F., 2009. A Scientific Perspective of Digital Human Models: Past, Present, and Future. In V. G. Duffy, ed. Handbook of DIGITAL HUMAN MODELING, USA: Taylor and Francis, 3.1-3.26.

[37] Jäger, M., Luttmann, A., Göllner, R. and Laurig, W., 2001. The Dortmunder - Biomechanical Model for Quantification and Assessment of the Load on the Lumbar Spine. SAE Technical Paper 2001-01-2085. Available from: http://www. http://papers.sae.org/200101-2085. [Abstract Accessed 2 July, 2012].

[38] Chaffin, D. B., 2009. Some Requirements and Fundamental Issues in Digital Human Modeling. In V.G. Duffy, ed. Handbook of DIGITAL HUMAN MODELING, USA: Taylor and Francis, 2.1-2.10.

[39] Bubb, H., 2007. Future Applications of DHM in Ergonomic Design. In V.G. Duffy, ed. Digital Human Modeling, LNCS 4561, Springer, 779-793.

[40] Rider, K., Park, W., Chaffin, D. and Reed, M., 2003. Redesigning Workstations Utilizing Motion Modification Algorithm.SAE Technical Paper 2003-01-2195. Available from: http://www. http://papers.sae.org/200301-2195. [Abstract Accessed 2 July, 2012].

[41] Peacock, B., Reed, H. and Fox, R., 2001. Ergonomic Analysis of Sheet-Metal Handling. In D. B. Chaffin, ed. Digital Human Modeling for Vehicle and Workplace Design, USA: SAE, Inc. ISBN 0-7680-0687-2, 113-126.

[42] Sundin, A., Christmansson, M. and Larsson, M., 2004. A different perspective in participatory ergonomics in product development improves assembly work in the automotive industry. International Journal of Industrial Ergonomics, 33, 1-14.
[43] Demirel, H. O. and Dufy, V. G., 2007. Applications of Human Digital Modeling in Industry. In V.G. Duffy, ed. Digital Human Modeling, LCNS 4561, Springer, 824832.

[44] Lämkull, D., Ortengren, R. and Malmslöld, L., 2009b. Digital Human Modeling Automotive Manufacturing Applications.In V.G. Duffy, ed. Handbook of DIGITAL HUMAN MODELING. USA: Taylor and Francis, 42.1 42.17 .

[45] Gabriel, R. F., 2003. What engineers and managers need to know about human factors.Warrendale PA: SAE International.ISBN: 0768009758.

[46] Vink, P., Koningsveld, E. A. P. and Molenbroek, J. F., 2009. Positive outcomes of participatory ergonomics in terms of greater comfort and higher productivity.Applied Ergonomics, 37, 537-546.

[47] Chaffin, D. B., 2005. Improving Digital Human Modeling for Proactive Ergonomics in Design. Ergonomics, 48(5), 478-491.

[48] Chaffin, D. B., 2001. Summary. In D. B. chaffin, ed. Digital Human Modeling for Vehicle and Workplace Design, USA: SAE, Inc. ISBN 0-7680-0687-2, 137-146.

[49] Hanson, L., Blomé, M. Dukic, T. and Högberg, D. 2006. Guide and documentation system to support digital human modeling applications. International Journal of Industrial Ergonomics, 36, 17-24.

[51 ]Luximon, Y., Ball, R. and Lorraine Justice, L., 2012. The 3D Chinese head and face modeling. Computer-Aided Design, 44, 40-47.

[52 ]Baek, S. Y. and Lee, K., 2012. Parametric human body shape modeling framework for human-centered product design. Computer-Aided Design, 44, 56-67.

[52] Laring, J., Christmansson, M., Davidsson, A., Dukic, T., Falck, A.C. and Hanson, L., 2005. Simulation for manufacturing engineering (ViPP). In SAE Transactions Journal of Materials and Manufacturing114(5), SAE 2005-01-2696, 884-889.

[53] Paul, G. and Wischniewski, S., 2012. Standardisation of digital human models. Ergonomics, 55(9), 1115-1118. 